\title{
Library User Survey: Based on the Humanities and Social Sciences at the University of Jaffna
}

\author{
Kirupa Hoole \\ Acquisition Library, University of Jaffna, Sri Lanka
}

Copyright $\subset 2017$ by authors, all rights reserved. Authors agree that this article remains permanently open access under the terms of the Creative Commons Attribution License 4.0 International License

\begin{abstract}
The study involves ascertaining the users' views of the resources and services available in the main library. The survey was conducted among the students from the Humanities and Social Sciences that are two among the main divisions, apart from aesthetic studies, that make up the Faculty of Arts. The main instrument of the survey was a questionnaire that was given to a sample of students, the data obtained from which was then analysed by appropriate statistical techniques. The study reveals that there is at the core a positive relation between the level of satisfaction among the students of the Social Sciences and Humanities and the usage of the Library, taken together with key facets ranging from resource collection to library environment, attitude of the staff and the services on offer. They have also indicated additional \& existing services that would add quality to their library use. The University of Jaffna faces the challenges of a region in developing country that needs to move forward and put behind it the deleterious effects of 30 years of violence and war. The war leading to relative isolation of the region and exodus of academically competent members of the staff, inevitably posed a severe challenge to the upkeep of standards in a university that showed much promise in the early 1980s. The principal challenge facing the Library, in addition to catering to the information needs of staff and students, is to motivate students to read independently, use the facilities of the Library to enhance and satisfy their curiosity for knowledge and give us a more enlightened generation that would enable the intellectual recovery of the region to be self-sustaining.
\end{abstract}

Keywords User Survey, User's Need, Staff Attitude, Library Services, University Libraries

\section{Introduction}

The main objective of university libraries is to support the teaching, learning and research needs of the students and staff in ways consistent and supportive of the institution's mission. To this end our library has among its goals theinculcation of knowledge at student level, assisting professional development at staff level and the preservation and replenishment of the society's culture.

Against this backdrop, Academic Libraries played an essential role in setting standards for libraries and catering to information needs of academics and students. They served as a focal point in providing users what they seek, either by collecting and organizing information within the Library or through cooperative arrangements with other libraries.

Over the years, the medium of information has undergone changes from ancient tablets and scrolls to Gutenberg's printing technology for books in the $15^{\text {th }}$ century leading presently to audio visuals and CD ROMs. These developments, along with the provenance of electronic documentation and Internet, shifted the Library's collection development from information storage to information access.

To explain, the advancement of information and communications technology in the last four decades motivated libraries all over the world to incorporate IT based facilities in the services they offer. As a result, expectations from services have also expanded in breadth and magnitude particularly in developed countries. However, in the developing countries, apart from the traditional services, adaptation to digital mode moves at a slower pace although, we have progressed from automation of the library systems to access to online information, according to user needs and preferences, including expeditious searches locally and globally. The information needs and expectations of users are changing rapidly. Thus providing library services has become more challenging even in developing countries.

The University of Jaffna faces the challenges of a region in developing country that needs to move forward and put behind it the deleterious effects of 30 years of violence and war. The war leading to relative isolation of the region and exodus of academically competent members of the staff, inevitably posed a severe challenge to the upkeep of 
standards in a university that showed much promise in the early 1980s.

Looking forward under these circumstances, the principal challenge facing the Library, in addition to providing the staff and students' information needs, is to motivate students to read independently, use the facilities of the Library to enhance and satisfy their curiosity for knowledge and give us a more enlightened generation that would enable the intellectual recovery of the region to be self-sustaining rather than just exam passers.

With a view to the formulation of a course of action that would advance this recovery, this study by means of a user survey designed to find out how our services match user needs. The data collected and analysed gives us an indication of where to begin (see Methodology below).

\section{User Surveys}

Libraries have conducted periodic surveys from the beginning of the $20^{\text {th }}$ century. According to Siatri (1999), user studies in library and information sciences emerged in the late 1940s and have continued to progress rapidly since then in conjunction with research developments in related fields.(1)

"Historically the quality of academic libraries had been evaluated on the basis of richness of collections and the space they possess, whereas the element of quality services had been largely ignored" (2) as expressed by Nitecki.

In the past few decades, quality of user services has been given greater importance, based on users' perceptions and expectations. The concept of Total Quality Management (TQM) and other Management techniques have been incorporated in evaluating service qualities in Libraries \& Library Management.

Several theories and practices were developed on this theme by the great librarians who were library educators, researchers\& information specialists. Among them are Lancaster, Baker, Webster, Cook, Thompson and several others who pioneered library assessment activities and developed library evaluation methods which were followed by other library leaders in the $21^{\text {st }}$ century like Webster, Hiller, Nitecki, Franklin, Choudry, Zeithmal, Parasuraman, Berry and several others, who wanted "new measures" like Libqual, Servqual and Digiqual. (3)

In the West it has been the practice to do user surveys periodically, at least annually, to update user needs. The University of Jaffna has in keeping with user needs upgraded its services over the years to, in addition, improve traditional services such as the usage of available materials and student support services.

The Humanities\& Social Sciences Faculty provides at undergraduate level three year general and four year special degree courses. Excepting the Law Department which uses English, the courses in all other departments are conducted in the Tamil medium and the student strength in these courses comes to about 2050.

\section{Library Resource Collection}

The Jaffna University Library has a modest collection of about 1,60,000 (1.60 lakhs) books that cover the whole spectrum of subjects taught in the different faculties of Arts, Science, Medicine, Management, Agriculture and Engineering. The Social Sciences\& Humanities collection comprises around $63 \%$ of the total. Of the latter, about $40 \%$ of the books are in Tamil. The Automated Library System LIBSYS has been in service from 2005, for users to search the entire bibliographic records of books available through OPAC. The database of books available in the library is being updated on day to day basis with details of recently acquired books.

Many of the books in the Humanities and Social Sciences were donated by eminent academics and well-wishers concerned with the development of Jaffna University. More than $50 \%$ of the Tamil books we have been published after 1980 and $20 \%$ after 2000 .

The Library subscribed to about 40 Tamil magazines and journals, both local and foreign, and about 106 print \&11online journals in English this year

The Medical faculty has access to online resources through HELLIS network. Moreover, through HINARI the medical and agriculture faculties obtained access to some additional databases. Again, since last year, the UGC-initiated Library Consortium provided online access to journals through a few renowned publishers to all academics\& students. In India of course, Library consortia for online databases had been in operation from the 90 s for Universities and Institutions, with UGC support

When it comes to e-resources in Tamil, there is limited access to online materials for the Social Sciences and Humanities. This reveals that the students are more dependent on the university library and special libraries for information resources.

\section{Objectives of the Study}

The main objectives of the survey are to provide an efficient support service that would enable the students of Humanities and Social Sciences to acquire the information they seek and to identify the facilities and user services that would enable them to utilize the library flexibly and effectively. To this end the survey seeks to find out:

1. The level of usage of the library by the students of the Social Science \& Humanities

2. Their needs and expectations as regards services and resources

3. Customer care observed by the library reader service

4. User awareness of the available facilities

5. What other services that could be provided within our limits 


\section{Methodology}

The methodology chosen to study the above is a survey requiring a sample of users to answer a questionnaire designed for the purpose of gaining insight into the various factors that are being studied and to determine the users' views and the usage of the resources and the services.

The user survey was conducted among the General \& Special Degree students from the Social Sciences and Humanities, namely the Faculty of Arts in the University of Jaffna. The Social Sciences \& Humanities has a population of 2053 from both the General \&Special Degree programmes,

\section{Sample}

The Faculty of Humanities\& Social Sciences with about 23 departments and a corresponding number of courses, conducts three-year general and four-year special degree programmes and the courses in all departments are conducted in the Tamil medium other than in Law.

Random samples comprising about $25 \%$ of students were selected from each programme in the year 2014/15 and the questionnaire was distributed to about 500 students from the Humanities and Social Sciences. The closed set of questionnaire was structured to obtain information on the utilization of services available in the Main Library and their levels of satisfaction.

The questionnaire sought information on the purposes of the students' visits to the Main Library, the resources utilised, about the reference collection, the customer care of the staff, the environment related to space, ventilation, silence and privacy, the services provided by the library and what else they like to have. The questionnaire was distributed in lecture halls and there were 397 respondents $(80 \%)$. The collected data was analysed to find answers to the questions posed above.

\section{Literature Review}

We review some studies from Third World countries that are more immediately relevant to our setting.

Gunasekera C (4) from University of Peradeniya, Sri Lanka, conducted a survey to find out the user needs of the undergraduates and the usage of the library by them. The study revealed that the undergraduates showed satisfaction with the resources, services and other facilitates available. However, the findings show that the resources and services are not adequately utilised. She says this may be because the undergraduates are not aware of the services or not considered them important for their studies. As a result she concludes saying that the library needs to promote awareness and use of electronic information sources by conducting comprehensive information literacy programmes.
She also suggested to increase the acquisition of electronic information resources while continue to acquire general and reference materials that the library needs.

On the physical environment also she said that the ventilation for the reading environment should be improved. On the staff-customer relation she says the library has to take measures to improve the relationship as well as to train the staff on customer relations. She concluded saying that the library should conduct user surveys regularly to improve the services towards a user centered library and information service.

In a study conducted at University Teknologi, MARA (in Malaysia) by Kassim NA, Zakaria K (5), cited in Kassim NA (6), in order to find out how the libraries could help with the users' learning \& research needs, it was revealed that about $40 \%$ of them expect the libraries to provide more of the recent publication, $18.9 \%$ prefer longer opening hours, $16.1 \%$ prefers more PCs in the Library for customers, $13.3 \%$ suggested that the staff should be more friendly and knowledgeable, where $7.5 \%$ wanted the library to organize more workshops on how to find information while $2.8 \%$ suggested Library should provide guidance \& consultation on research methods \& the Library to develop its internet information was highlighted by $2 \%$.

They went on to say that the largest proportion $(91.7 \%)$ of the respondents think that the Library should publish a guide on information searching. Further, large proportions $(89.6 \%)$ of the respondents feel that the library should publish library and information related journals. A high proportion of the respondents desire publication of a periodically updated index and bibliographies to aid lifelong learning. The researcher felt that such activities could call upon the aid of other sections of the academic community as well. Examples of these are workshops on study methods, study skills, problem solving techniques, examination techniques, critical thinking and lifelong learning.

Norlia (6) emphasized in one of his findings that the role of the library as a place of learning and of access to information is as valid as ever. To encourage a positive learning environment, the management should encourage the staff to participate in a range of educational activities, for staff who take the initiative to enhance their skills. Moreover, Norlia suggested that the library do benchmarking to compare the library's performance with the aim of improving the library's performance by adopting the best practices from the others.

A survey of University libraries in Pakistan, conducted by Shaflique F., Rehman S-ur-, Mahmood K (7), (2012) at the Punjab Province \& the Islamabath community territory of Pakistan, on the user's needs , satisfaction and Library performance reveals , although the respondents have shown their overall 
satisfaction they were not actually satisfied with their respective library services. The user's view of the library services, staff and the environment turned out to be satisfactory. Most of them seem to visit the library at least twice a week. The users are quite satisfied with the digital collection, online books, databases and periodical literature is due to the digital resources available to the University Libraries provided by the Higher Education Commission of Pakistan (HEC).

Sahu (8) (2007) carried out a study at Jawaharlal Nehru University library, to measure the perceptions and expectations of library users. The results of the study were encouraging, as they indicated that users of the library were largely satisfied with various aspects of the services and their quality, although there is a need for promoting the optimum use of available resources and services, as some of the users, the study found, were unaware of them.

In order to promote information literacy skills among students, University of Colombo has been conducting an information literacy course module for science undergraduates. Somaratna (9), in her assessment report deems the module a success in promoting effective reading and creative writing among students. Training workshops have been effective in fostering information literacy, ability to perform Literature searches and skills in taking down notes.

\section{Questionnaire \& the Sample Data}

The students were basically asked for their views on the following:

\section{Variables of library usage}

The sample data comprised answers to the questionnaire by respondents, from which were derived priority indices of respondents (variables of library use) representing functions as borrowing, reference, newspapers, photocopying, and English Reading (Develop competence in English usage).

\section{Variables of satisfaction and adequacy of resources}

Respondents were asked to rate their satisfaction with resources: Reference collection, Books in Stacks for loan, Archives, audio-visuals \& e-resources \& also adequacy of recent acquisitions in their subject areas in both Tamil \& English

\section{Levels of satisfaction with the Library environment}

Study Area, Shelf arrangement of Books, Lighting, tranquility and conduciveness, security, service hours, photocopying facility

\section{The customer care by library staff}

Staff's attitude towards customers at service points: at the circulation desk, overall willingness to help, help with search of required item in the Library, help with queries related to their assignments

\section{Library Services}

Respondents were asked to give their satisfaction level on the Number of Books given for Borrowing, the usefulness of the monthly added Accession list, information on the OPAC, Effectiveness of Orientation programme and the adequacy of User Guide prepared by the library.

\section{What other services would they like the Library to provide}

Respondents were asked whether they prefer services such as internet access, Information literacy programmes/courses, guidance in searching, assistance in carrying out researches, facility for Group activities, Inspirational talks on general knowledge topics, more books for General reading or good films both Educational and recreational.

There were $80 \%$ responses from students and we have tabulated all 397 students' responses and obtained the following:

\section{Analysis of Data}

The students were basically asked for their views on the following:

1 The Purpose of coming,

2. About the resources collection - (books, journals, audio-visuals\& e-resources etc)

3. Library environment (Study Area, Lighting, quietness, Shelf arrangement, Open hours etc)

4. The customer care of staff

5. Library Services

6. What other services would they like the Library to provide

We have tabulated all 397 students' responses and obtained the following:

\section{The Purpose of coming}

The responses indicated, for both humanities and social sciences, most of them came mainly to borrow books and to do reference.

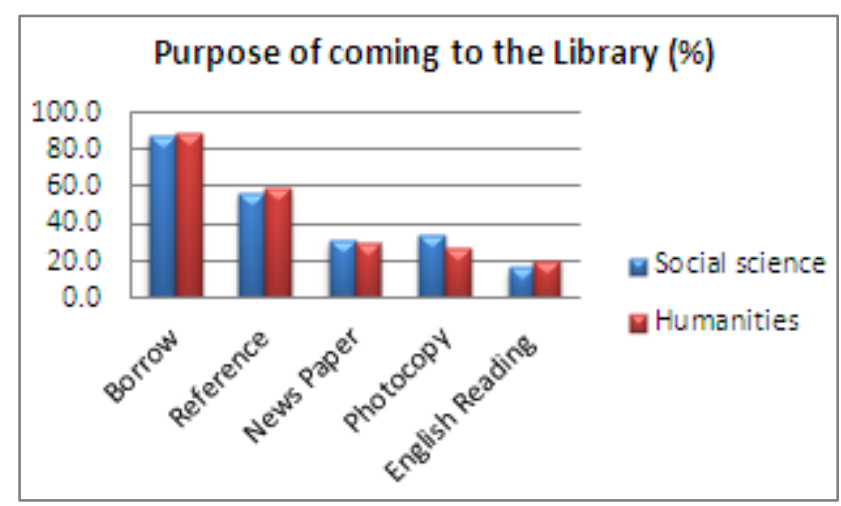

In the Humanities $87 \%$ of respondents say they visit the library with the intention of borrowing books and $58 \%$ of 
them for reference while $30 \%$ for reading newspapers and another $30 \%$ for photocopying.

In the case of Social sciences, $85 \%$ of respondents say they visit the library to borrow books and $55 \%$ of them for reference while only $30 \%$ for reading newspapers and $30 \%$ of them say for photocopying.

To promote English reading and writing, the library issues the students additional 2 tickets. Only $24 \%$ in the Social Sciences\& $28 \%$ in the Humanities appear to use these facilities.

\section{Resources Available}

When asked how much the resource collection is helpful to them in their studies, the students answered in the following manner.

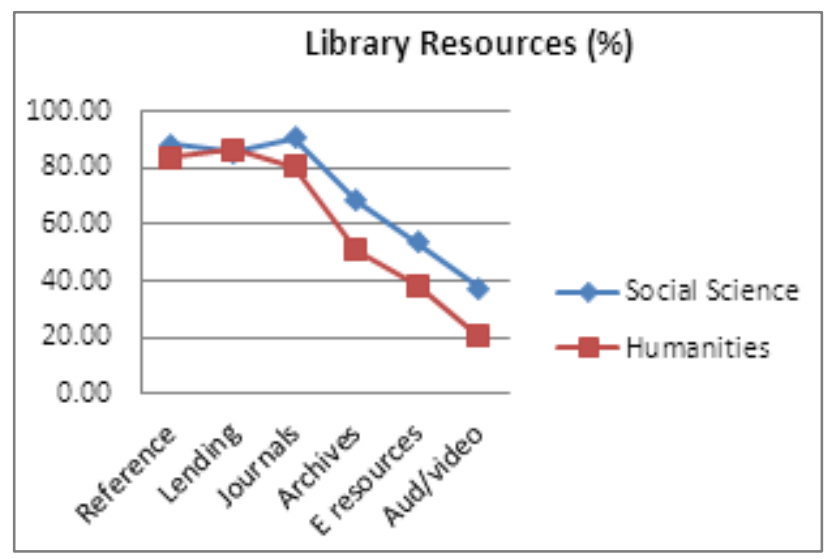

The students' view of the collection is that they are overall satisfied with the print collection. We find that there is a co-relation between the Humanities (Hum) \& Social Science (Soc.Sc.) students, in their views about the usefulness of the collection.

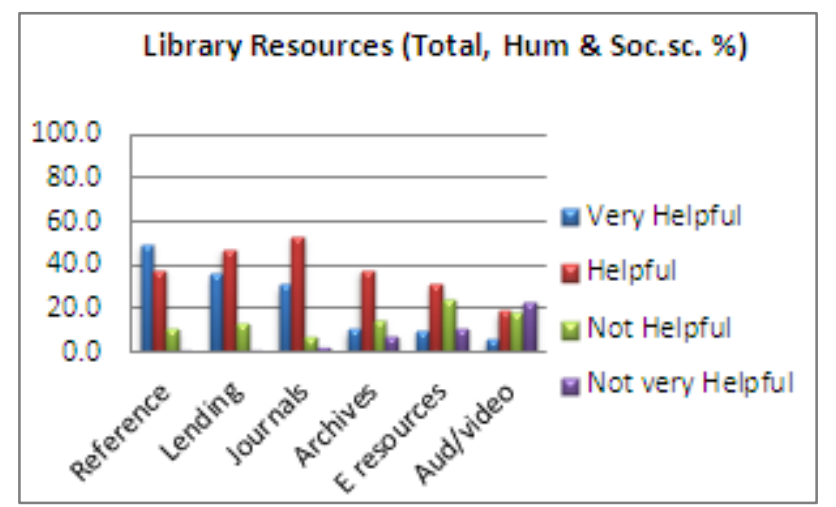

From the total of both categories more than $50 \%$ of students say the reference collection is very helpful, $35 \%$ say they are helpful and only about $10 \%$ feel it is not helpful.

About $70 \%$ of the users say, they are satisfied with the lending collection while only a $10 \%$ are dissatisfied.

About the periodicals, nearly $80 \%$ of the students feel they are either helpful or very helpful and only about $10 \%$ feel they are inadequate for their needs. The students use the Tamil journals and magazines substantially for assignments and report writing. Most of the journals subscribed to are in English. Particularly, for the Soc.Sc \& Hum, we have relatively a few Tamil journals and magazines, both local and foreign. But students consider them useful for reference. There is an article Index for Tamil journals that are entered into Libsys database and available through OPAC.

Archival collection comprises Government documents, Reports, Pamphlets and Sri Lankan materials. \& rare books. Only $45 \%$ say they are satisfied and nearly $25 \%$ feel they are not helpful.

The students feel that they should have access to more e-resources in Tamil. More than 50\% of them feel the e-resources would be more helpful to them. By e-resources, we mean access to On-line full-text journals, databases, e-books, online Indexes, dictionaries, encyclopedias, \& Newspapers. Links to useful websites that give free access are given on the Library website. From 2014 the UGC has organised Library consortium for all the universities that give access to a few e-journals and databases that are more useful for the staff. But these are materials available only in English and most of the Soc.Sc.\& Hum students don't find them helpful. Of course there are a handful of students who could refer books \& e-resources in English for reference, but not many. The e-resources available in Tamil have their limitations, though some expatriate organisations that promote literature in Tamil are trying to create e-versions of some of the popular and rare books, reports and magazines in Tamil to provide e-access to some of the collections. Noolaham is one such organisation that provides e-book facilities to some of the rare scholarly collections in Tamil.

Though not well used the audio-visual collection contains materials of educational value that also enhance general knowledge.

About the Availability of Text Books published recently:

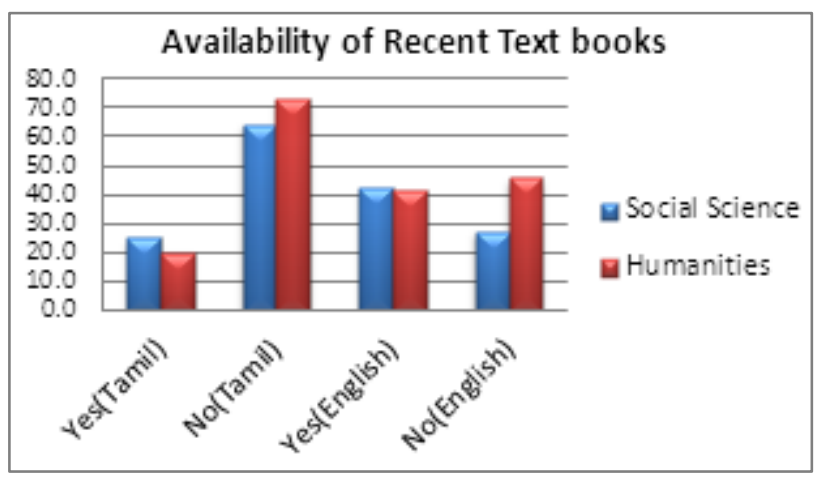

The students feel that recent publication in Tamil are not enough. The quantity of recent books in Tamil is inadequate for reference according to about $75 \%$ of both Soc. Sc.\& Hum students. About $30 \%$ of both the Soc. Sc. \& Humanities Students feel even in English, recent publications are not adequate. 
Although there is a large literary output of books in Tamil after 2001, particularly by individuals, there are fewer books of repute catering to students at University level.

\section{The Library environment}

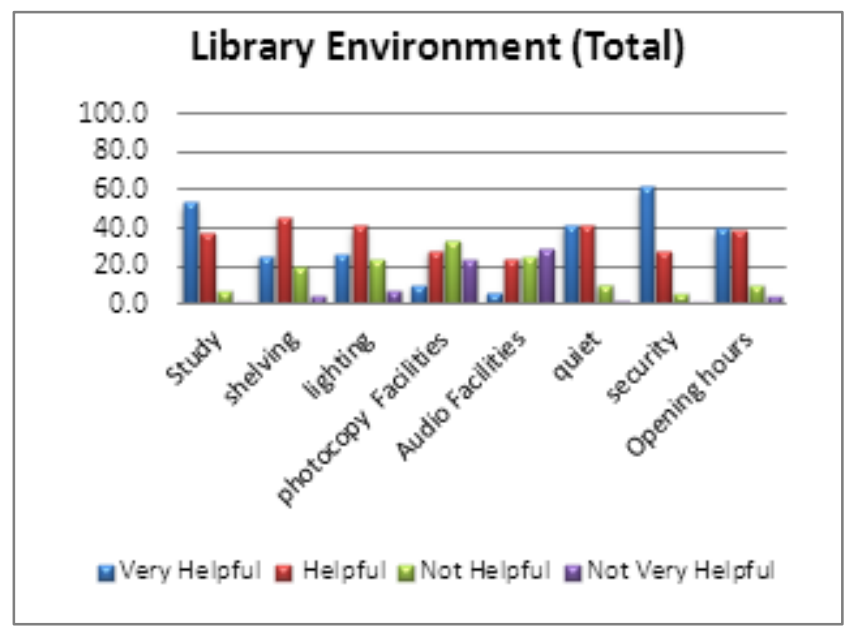

\begin{tabular}{|c|c|c|c|c|c|c|}
\hline $\begin{array}{c}\text { Library } \\
\text { Environment }\end{array}$ & $\mathrm{a}$ & $\mathrm{b}$ & $\mathrm{c}$ & $\mathrm{d}$ & $\begin{array}{c}\text { total } \\
\text { response }\end{array}$ & Mean \\
\hline Study Area & 212 & 149 & 27 & 5 & 393 & 3.45 \\
\hline shelving & 101 & 183 & 79 & 18 & 381 & 2.96 \\
\hline lighting & 102 & 164 & 91 & 29 & 386 & 2.88 \\
\hline Photocopy & 40 & 110 & 133 & 91 & 374 & 2.26 \\
\hline Audio visuals & 25 & 94 & 97 & 115 & 331 & 2.09 \\
\hline quiet & 167 & 165 & 41 & 8 & 381 & 3.29 \\
\hline security & 244 & 112 & 21 & 5 & 382 & 3.56 \\
\hline Opening hours & 158 & 156 & 40 & 17 & 371 & 3.23 \\
\hline
\end{tabular}

$\mathbf{a}=$ Very Helpful $\mathbf{b}=$ Helpful,

$\mathbf{c}=$ Not Helpful $\mathbf{d}=$ Not Very Helpful\& the Scale used : $\mathbf{a}=\mathbf{4}, \mathbf{b}=\mathbf{3}, \mathbf{c}=\mathbf{2} \&$ $\mathbf{d}=\mathbf{1}$

As to the atmosphere of the Library, there is considerable agreement among the Social Sciences and Humanities. The Humanities students however strongly feel that the photocopying service is not adequate.

The overall atmosphere of the library is conducive for students to do their references.

About the study area(mean =3.45), quietness of the place (mean $=3.29$ ), opening hours (mean $=3.23$ ), and security (mean $=3.56$ ) for belongings the satisfaction level is about or above $60 \%$.

More than $80 \%$ of the students are satisfied with the study area, quietness, security and opening hours of the library. Shelving (mean $=2.96$ ), \& lighting of the place (mean $=2.88$ ), the satisfaction is about the average. Photocopying (mean $=2.26$ ) and audio visual facilities (mean $=2.09$ ), satisfaction level is below $40 \%$.

The ventilation and lighting need to be improved and shelving is done at regular intervals.

Responses of more than $70 \%$ indicated dissatisfaction with audio visual facilities and photocopying.

\section{Customer care of the Library Staff}

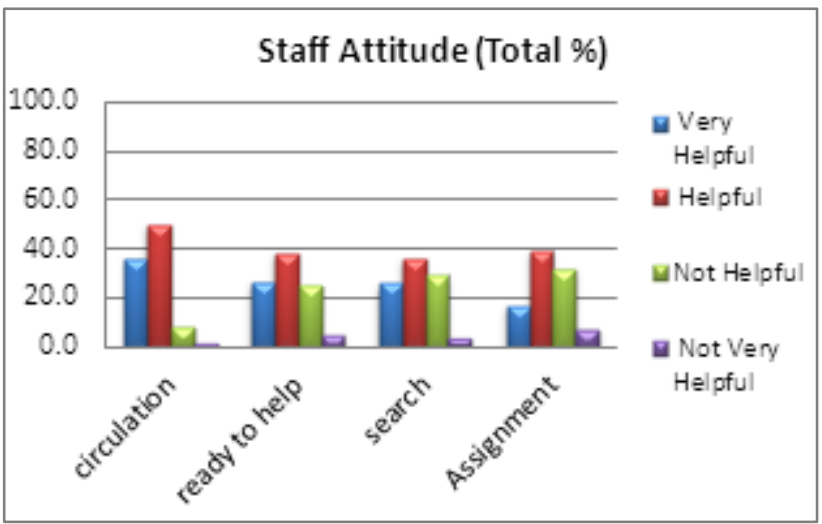

$90 \%$ of students commend the accommodativeness of the counter staff.at the circulation desk.

The students are generally satisfied with the staff's responses to their queries and attitudes towards them when approached, or even about other enquiries.

For OPAC search and related to other evaluations the amount of help they expect is more. About $60 \%$ are satisfied while the others are not.

The students expect more guidance and instructions to carry out their assignments and research. About $55 \%$ of them are satisfied while others strongly feel some guidance \&assistance is necessary for them to find out what they seek for.

\section{Library Services}

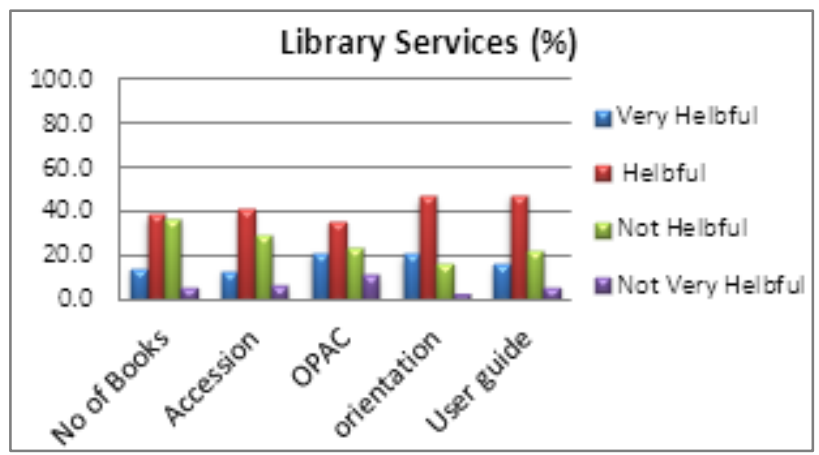

When asked about the helpfulness of the services, the students expressed general satisfaction. About $50 \%$ are happy with the adequacy of the number of tickets given for borrowing. Only about $50 \%$ find the accession list which gives the monthly addition to the library helpful.

Most of the students from both Soc.Sc.\& Hum have the same feeling that about $50 \%$ of them are satisfied with the OPAC. Orientation programme and the user guide, catalogues and index of articles that are available at the Library, above $60 \%$ are happy and find it useful but about $25 \%$ don't feel that they are helpful. 


\section{What other services would they like}

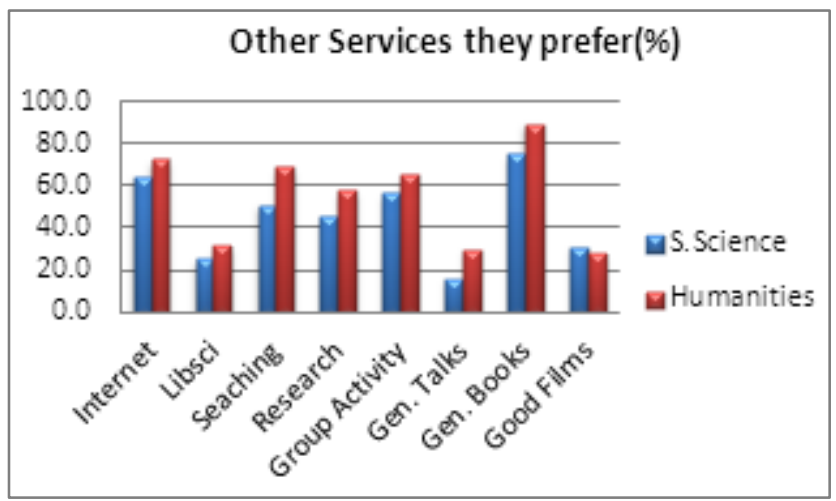

When asked what else would they like to have more than $60 \%$ of both Social Science and Humanities students prefer Internet access, more help in OPAC search and in doing their research. They would expect guidance in carrying out research or doing assignments, help in doing efficient searches for materials, facilities to work in group.

About $40 \%$ feel that greater effort in familiarising students with library practices \& available resources would help them to use the Library collection more effectively.

In order to improve their general knowledge, $90 \%$ of them are with the view of having good books, and not many feel good films or inspiring talks could broaden their understanding of society and knowledge, but only a $30 \%$ believe in it.

\section{Circulation Statistics}

The students are given two tickets each for borrowing and one for reference for the $1^{\text {st }}$ year with an additional ticket added every year. Two green tickets are also given to promote general reading in English

The circulation statistics for lending of books shows that, in 2014 , the total number of loans of books was 8,467 for the Social Sciences and 6,260 for the Humanities. The numbers for Reference are respectively $1,757 \& 1,442$.That brings us to the fact that whichever way one interprets it, the utilization of library resources and services by students could be promoted. Even the figure for general English reading and writing is not at all impressive.. The in-house statistics shows the usage of reference \& Permanent reference is fair. It would appear that some students are removing books from shelves for reference and photocopying of sections, while others depend on notes and study packs given to them. The attitude reflected is suggestive of students motivated largely towards passing examinations rather than a critical acquisition of knowledge.

\section{Conclusions}

The study reveals that there is at the core a positive relation between the level of satisfaction among students of the Social Sciences and Humanities in the usage of the Library and the key facets ranging from resource collection to library environment, attitude of the staff and the services on offer. They have also indicated additional services that would add quality to their library use.

The study reveals that more funds should be allocated for books to each department, since there is a paucity of adequate text books and recent publications \& the number of departments in the Arts faculty is above 20.

Besides, the orientation programmes could be more creative, thought provoking \& knowledge stimulating, thus enabling users to understand library services and find inspiration from the available resources to search and read more creatively. Building students' confidence in using the Information retrieval system (OPAC) is important as both categories of students who study almost exclusively in Tamil depend crucially on the library collection, their study materials and on other libraries around. Interactive course related awareness through workshops \& non-credit courses on information literacy would enable more gainful utilisation of the library.

Need for promoting the available resources is equally important

The study concludes with the following suggestions to improve the level of usage and enhance their utilization of the library resources for their educational and research needs, in the areas given below.

A. Resource collection should be enhanced by:

1. More text books in Tamil with updated editions

2. Recent books in Tamil for supplementary reference

3. Scholarly journals in Tamil should be subscribed to

4. e-resources with internet access

5. General books, for reading promotion

B. About OPAC searches:

1. Guidance to make OPAC Searches more efficient with advance searches

2. Promotion of Library collection for efficient search results and better usage

3. Organize Library collection, with indexing articles and documentation

4. A Thesaurus on Social science and Humanities could help the students immensely.

5. Editing the Library OPAC with better structured key words would improve the search recalls, thus getting maximum benefit from the available collections.

C. About Skills Development:

1. Training workshops on information skill development

2. Creating a learning environment

3. Improving Orientation and making greater awareness of information literacy

4. Training on effective reading \& Creative writing

5. Non-credit programme on course related 
information literacy \& guidance to awareness to do Literature search and taking down notes

6. Biographical, Historical \& Inspiration series of lectures \& films for students to select their role models among great thinkers \& Philosophers and Inventors. Organizing educational talks or popular films to broaden Students' general knowledge

7. Reading for recreation and contribution towards social development

8. Promotion of the reading habit should not only aim at undergraduates but also the schools.

\section{Services}

Many respondents called for better photocopier services and improved internet access.

On a final note, the role of the Library must form an integral part of building up the students' ability to broaden their knowledge through proper guidance, which would enable them to develop their skills and academic stature; whence to enter society as better citizens who would guide our children to live in harmony with others and to support them to become guides and creative writers who value other human beings and do their bit in the development in a vision for a just society that is not weighed down by conflict.

\section{REFERENCES}

[1] Siatri R, The evolution of user studies. Libri, 1999; 49: 132-41.

[2] Nitecki DA. May (1996), Changing the concept and measure of service quality in academic libraries, Journal of Academic Librarianship, 1996; 22(3): 181-90.

[3] Kyrillidou M, Cook C, The Evolution of Measurement and Evaluation of Libraries: A Perspective from the Association of Research Libraries. Library trends,2008 Spring; 56(4); 888-909

[4] Gunasekera C, Students Usage of an academic Library: a user survey conducted at the Main Library University of Peradeniya, Journal of the University Librarians Association of Sri Lanka. 2010; 14 (1),43-60

[5] Kassim NA, Zakaria K, Users' Perceptions on the Contributions of UiTM Libraries in Creating a Learning Environment. Research Report. Shah Alam: Universiti Teknologi MARA, 2006

[6] Kassim NA, Evaluating users' satisfaction on academic library performance, Malaysian Journal of Library \& Information Science, 2009 Aug; 14(2): 101-15 Page

[7] Shaflique F, Rehman S ur, Mahmood K, (2012), A Macro sketch of users' needs, satisfaction and Library performance. A survey of University libraries in Pakistan, Library Philosophy \& practice [Internet], $2012 \mathrm{http}: /$ digitalcommon s.unl.edu/libphilprac/

[8] Sahu AK, Measuring service quality in an academic library: an Indian case study, Library Review, 2007; 56 (3), 234-43.

[9] Somaratna SD, A credit based information literacy course module for science undergraduates: an assessment, Annals of Library and Information Science, 2015 Mar; 60(3),19-26 